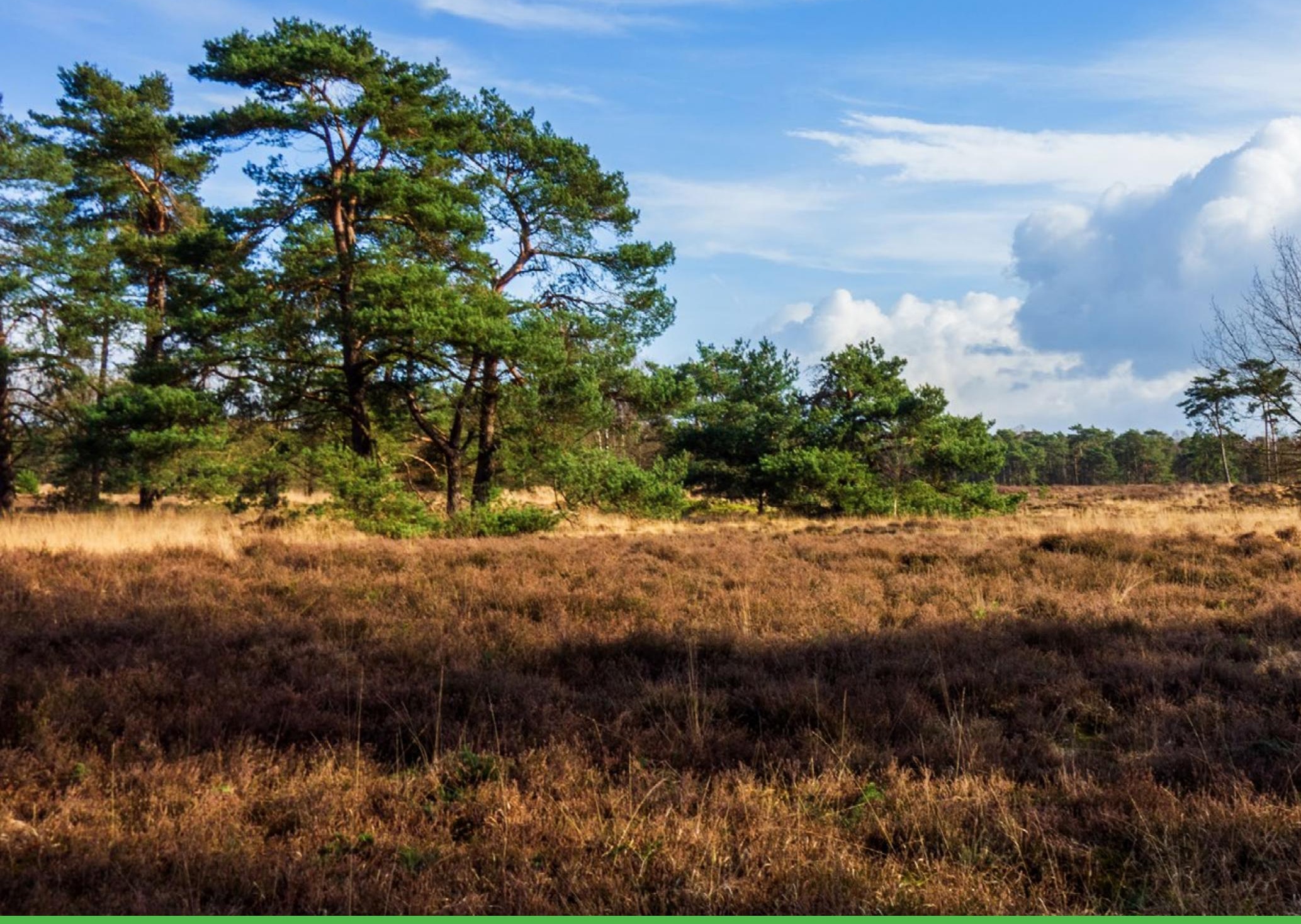

\title{
Kwaliteitsdocument van de Geomorfologische kaart van Nederland
}



Kwaliteitsdocument van de Geomorfologische kaart van Nederland 
Dit Technical report is gemaakt conform het Kwaliteitsmanagementsysteem (KMS) van de unit Wettelijke Onderzoekstaken Natuur \& Milieu, onderdeel van Wageningen University \& Research.

De WOT Natuur \& Milieu voert wettelijke onderzoekstaken uit op het beleidsterrein natuur en milieu. Deze taken worden uitgevoerd om een wettelijke verantwoordelijkheid van de Minister van Landbouw, Natuur en Voedselkwaliteit (LNV) te ondersteunen. We zorgen voor rapportages en data voor (inter)nationale verplichtingen op het gebied van agromilieu, biodiversiteit en bodeminformatie, en werken mee aan producten van het Planbureau voor de Leefomgeving zoals de Balans van de Leefomgeving.

\section{Disclaimer WOt-publicaties}

De reeks 'WOt-technical reports' bevat onderzoeksresultaten van projecten die kennisorganisaties voor de unit Wettelijke Onderzoekstaken Natuur \& Milieu hebben uitgevoerd.

WOt-technical report 195 is het resultaat van onderzoek gefinancierd door het ministerie van Landbouw, Natuur en Voedselkwaliteit (LNV). 


\section{Kwaliteitsdocument van de Geomorfologische kaart van Nederland}

W. Marijn van der Meij ${ }^{1}$, Gilbert J. Maas ${ }^{1}$

${ }^{1}$ Wageningen Environmental Research

BAPS-projectnummer WOT-04-013-013

Wettelijke Onderzoekstaken Natuur \& Milieu

Wageningen, december 2020

WOt-technical report 195

ISSN 2352-2739

DOI $10.18174 / 538255$ 


\section{Referaat}

Van der Meij, W.M., G.J. Maas (2020). Kwaliteitsdocument van de Geomorfologische kaart van Nederland. Wettelijke Onderzoekstaken Natuur \& Milieu, WOt-technical report 195. 40 blz.; 6 fig.; 3 tab.; 10 ref.

De Geomorfologische kaart van Nederland beschrijft de landvormen van het Nederlandse aardoppervlak. Deze kaart wordt momenteel geactualiseerd, omdat de nauwkeurigheid en het detailniveau niet meer aansluiten bij de huidige wensen van gebruikers. Dit document beschrijft het protocol dat gehanteerd wordt tijdens het actualiseren en de stappen die worden genomen om de kwaliteit van de actualisaties te waarborgen. De kwaliteitscontrole omvat een afstemming van de karteermethodiek bij aanvang van de actualisatie, een interne en een externe kwaliteitscontrole. Daarnaast geven we een kwaliteitsindicatie aan twee recentelijk geactualiseerde kaartbladen in Zeeland en op de Utrechtse Heuvelrug.

Trefwoorden: Geomorfologische kaart, kwaliteitstoetsing, BRO, Basisregistratie Ondergrond, geomorfologie

\section{Abstract}

Van der Meij, W.M., G.J. Maas (2020). Quality document for the Geomorphological Map of the Netherlands. Wageningen, The Statutory Research Task Unit for Nature and the Environment (WOT Natuur \& Milieu), WOt-technical report 195. 40 p.; 6 Figs; 3 Tabs; 10 Refs.

The Geomorphological Map of the Netherlands depicts the landforms in the Dutch landscape. The map is currently being updated because the accuracy and level of detail no longer match current user needs. This document describes the protocol for updating the map and the steps to be taken to assure the quality of the updates. The quality control involves fine-tuning the mapping methodology and an internal and external review procedure. In addition, we give an indication of the quality of two recently updated map sheets for areas in Zeeland and the Utrechtse Heuvelrug region.

Keywords: Geomorphological map, quality control, BRO, Key Registry of the Subsurface, geomorphology

Foto omslag: Shutterstock

\section{(C) 2020 Wageningen Environmental Research}

Postbus 47, 6700 AA Wageningen

Tel: (0317) 4807 00; e-mail: gilbert.maas@wur.nl

Wettelijke Onderzoekstaken Natuur \& Milieu (unit binnen de rechtspersoon Stichting Wageningen Research), Postbus 47, 6700 AA Wageningen, T 03174854 71, info.wnm@wur.nl, www.wur.nl/wotnatuurenmilieu.

WOT Natuur \& Milieu is onderdeel van Wageningen University \& Research.

Dit rapport is gratis te downloaden van https://doi.org/10.18174/538255 of op www.wur.nl/wotnatuurenmilieu. De WOT Natuur \& Milieu verstrekt geen gedrukte exemplaren van rapporten.

- Overname, verveelvoudiging of openbaarmaking van deze uitgave is toegestaan mits met duidelijke bronvermelding.

- Overname, verveelvoudiging of openbaarmaking is niet toegestaan voor commerciële doeleinden en/of geldelijk gewin.

- Overname, verveelvoudiging of openbaarmaking is niet toegestaan voor die gedeelten van deze uitgave waarvan duidelijk is dat de auteursrechten liggen bij derden en/of zijn voorbehouden.

Wettelijke Onderzoekstaken Natuur \& Milieu aanvaardt geen aansprakelijkheid voor eventuele schade voortvloeiend uit het gebruik van de resultaten van dit onderzoek of de toepassing van de adviezen. 


\section{Woord vooraf}

De Geomorfologische kaart van Nederland is onderdeel van de Basisregistratie Ondergrond (BRO). De BRO bevat verschillende ondergrondmodellen en ondergrondgegevens. Actuele ondergrondinformatie is essentieel voor de huidige ruimtelijke vraagstukken. Vandaar dat de Geomorfologische kaart van Nederland momenteel geactualiseerd wordt.

We willen graag Jasper Candel, Erik Meijles en Tom Harkema bedanken voor hun bijdrage aan dit project. $\mathrm{Zij}$ hebben als vakexperts meegewerkt aan de geomorfologische karteringen waarmee we de procedure voor de kwaliteitscontrole hebben ontwikkeld en de kwaliteitsindicatie hebben kunnen geven aan de recentelijk geactualiseerde kaarten in Zeeland en op de Utrechtse Heuvelrug. Daarnaast willen we Kim Cohen bedanken voor zijn review van de geproduceerde kaarten en dit document.

Marijn van der Meij en Gilbert Maas 



\section{Inhoud}

Woord vooraf

Inhoud

Samenvatting

Summary

$1 \quad$ Inleiding

2 Protocol geomorfologisch karteren

15

2.1 Inventarisatie van databronnen

15

2.2 Voorbereiding op het karteren

2.2.1 Theoretisch kader

2.2.2 Legendaopbouw

2.3 Stappenplan digitaal karteren

$\begin{array}{llr}3 & \text { Kwaliteitscontrole } & \mathbf{2 1}\end{array}$

$\begin{array}{lll}3.1 & \text { Procedure voor afstemming karteermethode } & 21\end{array}$

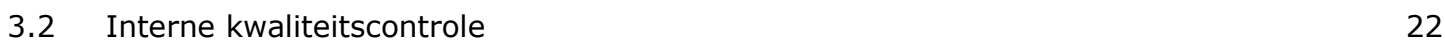

$\begin{array}{lll}3.3 & \text { Externe kwaliteitscontrole } & 23\end{array}$

$\begin{array}{ll}3.4 & \text { Afronding } \\ \end{array}$

4 Kwaliteitscontrole in de praktijk $\quad 25$

4.1 Visuele vergelijking karteringen $\quad 25$

$\begin{array}{lll}4.2 & \text { Samengestelde kaarten en karteerovereenkomst } & 29\end{array}$

$\begin{array}{lll}4.3 & \text { Conclusies } & 31\end{array}$

5 Conclusies $\quad 33$

$\begin{array}{lr}\text { Literatuur } & 35\end{array}$

$\begin{array}{lr}\text { Verantwoording } & 37\end{array}$ 



\section{Samenvatting}

De Geomorfologische kaart van Nederland beschrijft de vorm en ontstaanswijze van het Nederlandse aardoppervlak. Deze informatie is van belang voor ruimtelijke vraagstukken over klimaatadaptatie, natuurbeheer, infrastructuur en cultureel erfgoed, waar zowel ondergrond als bovengrond een belangrijke rol speelt. De kaart is daarom ook onderdeel van de Basisregistratie Ondergrond (BRO) en daarmee publiekelijk beschikbaar. De nauwkeurigheid en het detailniveau van de oudere kaartbladen van de kaart sluiten echter niet meer aan bij de huidige wensen van de gebruikers. Vandaar dat de kaart momenteel geactualiseerd wordt.

Om de kwaliteit van de toekomstige actualisaties te waarborgen, is dit kwaliteitsdocument opgezet. Dit document bestaat uit verschillende delen. Eerst wordt het protocol voor het geomorfologisch karteren beschreven. Hierbij wordt ingegaan op de gebruikte databronnen, de opbouw van de legenda van de geomorfologische kaart, de voorbereidingen die getroffen worden voor het karteren, waaronder een uitgebreide methode om de karteermethodiek onderling af te stemmen, en het uiteindelijke stappenplan voor het karteren.

Het afstemmen van de karteermethodiek gebeurt door verschillende geomorfologen hetzelfde pilotgebied te laten karteren. Door de geproduceerde kaarten op een kwantitatieve manier te vergelijken, kunnen landvormen en locaties waar de kaarten weinig overeenkomen geïdentificeerd worden. Voor deze locaties en vormen dient de karteermethodiek dan beter op elkaar afgestemd te worden. Tijdens het actualiseren zal de kwaliteit van de kaart gewaarborgd worden door een interne kwaliteitscontrole. Als de actualisatie is afgerond, zal de kaart aan een gebiedsexpert voorgelegd worden voor een externe review.

De methode voor de afstemming van de karteermethodiek is ontwikkeld in twee pilotgebieden, in Zeeland en op de Utrechtse Heuvelrug. Dit is gebeurd in samenwerking met geomorfologen van Wageningen University \& Research, Rijksuniversiteit Groningen en Utrecht University. De twee pilotgebieden zijn gekarteerd door verschillende geomorfologen. Door deze kaarten onderling te vergelijken, hebben we hieraan een kwaliteitsindicatie kunnen geven. De kaarten, geproduceerd zonder onderlinge afstemming, kwamen voor $60-70 \%$ overeen.

Door afstemming van de karteermethode, validatie in het veld en de kwaliteitscontrole zoals beschreven in dit document zal de actualisatie van de Geomorfologische kaart van Nederland leiden tot een consistent, nauwkeurig en gedetailleerd resultaat. 



\section{Summary}

The Geomorphological Map of the Netherlands depicts the landforms in the Dutch landscape and their genesis (processes of formation). This information is valuable for use when addressing spatial and land use planning aspects of climate adaptation, conservation management, infrastructure development and cultural heritage in which both the subsoil and the land surface are important factors. For this reason the map is a component of the Dutch National Key Registry of the Subsurface (BRO) and is publicly available. However, as the accuracy and level of detail of the older map sheets do not meet current user needs, the map is currently in the process of being updated.

This quality document has been compiled for the quality assurance of future updates and consists of several parts. The first is a description of the protocol for geomorphological mapping. This covers the data sources to be used, the contents of the map legend, the preparatory work required for the survey and mapping, including a detailed procedure for fine-tuning the mapping methodology, and a step-bystep mapping procedure.

The fine-tuning of the mapping methodology involves mapping of the same pilot area by various geomorphologists and a quantitative comparison of the resulting maps to identify landforms and locations where the maps differ significantly. The mapping methodology then needs to be fine-tuned for these locations and types of landforms. During the update the quality of the map will be assured by an internal quality control procedure. Once an update has been completed, the map will be reviewed by an external expert on the area in question.

The method for fine-tuning the mapping methodology was developed from an analysis of maps made for two pilot areas, in Zeeland and the Utrechtse Heuvelrug region, in collaboration with geomorphologists from Wageningen University and Research, the University of Groningen and Utrecht University. The two pilot areas were mapped by different geomorphologists and the resulting maps compared to derive an indication of their quality. Before fine-tuning, these maps showed a $60-70 \%$ correspondence.

Fine-tuning of the mapping methodology, validation in the field and quality control as described in this document will lead to a consistent, accurate and detailed update of the Geomorphological Map of the Netherlands. 



\section{$1 \quad$ Inleiding}

Geomorfologie is de wetenschap die zich bezighoudt met het bestuderen van de vormen van het aardoppervlak en de processen die bij het ontstaan daarvan een rol spelen of hebben gespeeld. De Geomorfologische kaart van Nederland 1 : 50000 beschrijft de in Nederland voorkomende geomorfologische eenheden en hun ontstaanswijze. Deze kaart wordt onder andere gebruikt bij ruimtelijke vraagstukken over klimaatadaptatie, natuurbeheer, infrastructuur en cultureel erfgoed (Climate Adaptation Services, 2018; Rensink et al., 2019).

Het grootste deel van de Geomorfologische kaart van Nederland is ontwikkeld tussen 1970 en 1990. Door middel van hoogtepuntenkaarten en uitgebreid veldwerk is twee derde van Nederland gekarteerd. Deze manier van karteren noemen we Kartering Oude Stijl. Tussen 1990 en 2003 zijn de resterende delen van Nederland gekarteerd. Voor deze karteringen waren er gedetailleerde digitale hoogtemodellen beschikbaar, waarmee de geomorfologie met meer nauwkeurigheid en detail gekarteerd kon worden. Het karteren met behulp van hoogtekaarten in een GIS-omgeving noemen we Kartering Nieuwe Stijl. In 2003 is de landsdekkende Geomorfologische kaart van Nederland gepubliceerd (Koomen and Maas, 2004).

De kaartbladen van de Geomorfologische kaart van Nederland die zijn vervaardigd aan de hand van Kartering Oude Stijl, voldoen niet meer aan de kwaliteitseisen die momenteel worden gesteld aan de Geomorfologische kaart van Nederland. Het detailniveau en de nauwkeurigheid van de afgrenzing van de landvormen zijn niet meer voldoende voor de doeleinden waarvoor de kaart gebruikt wordt. Deze kaartbladen zijn dus verouderd en worden daarom geactualiseerd. Hiermee is een begin gemaakt in 2009. Sindsdien is de kaart geactualiseerd in de provincie Drenthe, de provincie Zeeland, het Gelderse Rivierengebied, de Utrechtse Heuvelrug, de Veluwezoom en enkele losse kaartbladen in OostNederland. Deze kaartbladen waren het meest verouderd of zijn geactualiseerd op projectmatige basis. Een overzicht van het moment van publicatie van verschillende kaartbladen is te vinden in de online toelichting op de legenda van de Geomorfologische kaart (https://legendageomorfologie.wur.nl, Maas et al., 2019).

In de afgelopen jaren is het proces voor de actualisatie van de Geomorfologische kaart verder ontwikkeld en verfijnd. Voorbeelden hiervan zijn een herziening van de legenda van de geomorfologische kaart (Maas et al., 2019), het ontwikkelen van een karteerprotocol en het uitbreiden van de actualisaties naar gebieden onder bebouwing. Deze voorbeelden worden beschreven in dit document.

Sinds 2020 is de Geomorfologische kaart van Nederland onderdeel van de Basisregistratie Ondergrond (BRO). Met de opname in de BRO is de actualisatie van de kaart in een hogere versnelling gekomen, waardoor het belangrijker wordt de kwaliteit van de kaart te waarborgen. Dat is dan ook de reden dat dit kwaliteitsdocument is geschreven. Dit document bestaat uit verschillende delen. In hoofdstuk 2 wordt het protocol voor geomorfologisch karteren besproken. Dit protocol bevat de stappen die gezet worden in het maakproces van de kaart. Hoofdstuk 3 bespreekt de stappen die genomen worden om de kwaliteit van de actualisaties te waarborgen. De kwaliteitsprocedure is ontwikkeld in een studie, waarin is samengewerkt met geomorfologen van binnen en buiten Wageningen Environmental Research. Hoofdstuk 4 gaat in op de resultaten van deze studie en identificeert aandachtspunten voor de kwaliteitscontrole van de Geomorfologische kaart van Nederland.

Dit kwaliteitsdocument geldt als startpunt voor de actualisaties die in de komende jaren worden uitgevoerd. De ontwikkelde procedures die in dit document beschreven staan, zullen worden toegepast bij toekomstige actualisaties. De procedures kunnen aangepast worden naar nieuwe inzichten en met de ontwikkeling van nieuwe karteermethoden. Nadat de gehele kaart is geactualiseerd, zal de focus verschuiven van actualisatie naar onderhoud van de kaart. Dit document heeft geen betrekking op de onderhoudsfase van de kaart. 



\section{Protocol geomorfologisch karteren}

Dit hoofdstuk bespreekt het stappenplan voor het actualiseren van de geomorfologische kaart. Het protocol is opgedeeld in drie delen: het inventariseren van databronnen, de voorbereiding op het karteren en het karteren zelf. De stappen in dit protocol dienen als checklist voor de karteerder om ervoor te zorgen dat deze goed voorbereid aan het werk gaat.

\subsection{Inventarisatie van databronnen}

Het geomorfologisch karteren Nieuwe Stijl gebeurt voornamelijk in een digitale GIS-omgeving zoals ArcGIS of QGIS. In de GIS-omgeving kunnen verschillende databronnen over elkaar heen gelegd worden om landvormen met verschillende vorm en genese te onderscheiden. Er worden twee basisbronnen gebruikt voor het actualiseren van de geomorfologische kaart. Dit zijn digitale hoogtemodellen die het reliëf van het aardoppervlak laten zien en de oude geomorfologische kaart die geactualiseerd wordt.

De actualisatie van de geomorfologische kaart begint bij de oude versie van de kaart. Deze kaart geeft een goede indicatie van het type en de ligging van de geomorfologische vormen in een bepaald gebied. Door het detailniveau van de databronnen tijdens het karteren oude stijl (hoogtepuntenkaarten en veldwaarnemingen) sluit de afgrenzing van de vormen vaak niet aan bij de werkelijkheid en is het detailniveau van de kaart vaak te laag voor het beoogde gebruik. Dit is dan ook de reden dat de kaart geactualiseerd wordt.

Bij het actualiseren maken we gebruik van digitale hoogtemodellen om verschillende landvormen te onderscheiden en af te grenzen. We maken voornamelijk gebruik van het Actueel Hoogtebestand Nederland (AHN, https://ahn.nl), een landsdekkend, gedetailleerd digitaal hoogtemodel van Nederland waar elke vijf tot tien jaar een nieuwe versie van uitkomt. Voor het geomorfologisch karteren gebruiken we altijd de recentste versie van het AHN. Dat is op dit moment AHN3. Afgeleide kaarten van de hoogtemodellen, zoals hellingkaarten, reliëfkaarten en stroombanenkaarten geven extra informatie over de opbouw van het landschap en worden daarom ook bij de actualisatie gebruikt.

Bij het uitkomen van een nieuwe versie van het AHN hoeven geomorfologische karteringen die op vorige versies van het AHN zijn gebaseerd niet opnieuw geactualiseerd te worden, omdat de veranderingen in het Nederlandse aardoppervlak gering zijn over de tijd dat het duurt voor er een nieuwe versie van het AHN uitkomt. De veranderingen in de ligging en in reliëf van de landvormen zijn dus niet groot genoeg om er een andere classificatie aan te geven. Uitzonderingen hierop zijn geomorfologisch actieve gebieden, zoals buitendijkse rivier- en kustgebieden en gebieden waar veel bodemdaling optreedt, gebieden waar actief door de mens nieuw land wordt gemaakt, land wordt vergraven of land wordt ontpolderd. In zulke gebieden zal de geomorfologische kaart actief onderhouden moeten worden nadat de kaart landelijk geactualiseerd is.

Naast deze twee basisbronnen zijn er tal van andere bronnen die worden gebruikt bij het actualiseren van de geomorfologische kaart. Deze extra bronnen kunnen bijvoorbeeld informatie verstrekken over de genese van het aardoppervlak en de opbouw van de ondergrond. Daarnaast worden waar mogelijk ook andere fysisch-geografische karteringen gebruikt. De patronen op de digitale hoogtemodellen blijven echter leidend voor het afgrenzen van de landvormen.

In Tabel 1 staan voorbeelden van extra databronnen die momenteel worden gebruikt tijdens de actualisatie. Dit zijn bijvoorbeeld ondergrondgegevens en andere ondergrondmodellen uit de Basisregistratie Ondergrond, zoals de Bodemkaart van Nederland en geologische modellen zoals GeoTOP (https://broloket.nl/ondergrondmodellen). Daarnaast worden er ook recente en historische topografische kaarten gebruikt voor het vaststellen van landgebruik, wat vaak gerelateerd is aan de 
geomorfologie. De beschikbaarheid van de databronnen verschilt per gebied dat geactualiseerd wordt. Zo zijn geomorfologische, geologische en bodemkundige detailkarteringen alleen voor kleinere gebieden beschikbaar. Ook andere fysisch-geografische karteringen richten zich vaak op een bepaalde regio of landvorm (bijvoorbeeld Cohen et al., 2009; Landschapsbeheer Drenthe, 2020). Per gebied wordt er een praktische afweging gemaakt in hoeverre de eerder gebruikte bronbestanden toereikend zijn voor de actualisatie, in welke mate detailkarteringen hier waardevolle aanvullingen op kunnen zijn en hoeveel tijd er beschikbaar is voor de actualisatie.

De bronbestanden worden maximaal tot een schaal van 1:5.000 ingezoomd voor het herkennen, afgrenzen en classificeren van landvormen. Voor karteringen kleiner dan deze schaal zijn de databronnen vaak niet toereikend en is er aanvullende veldonderzoek nodig. Het gebruik van de bronbestanden op schaal 1:5.000 is ruim voldoende voor de geomorfologische kaart met kaartschaal 1:50.000. Deze kaartschaal komt overeen met een celgrootte van 5 meter voor rasterkaarten. Het AHN met een celgrootte van 5 meter is dus voldoende voor het actualiseren.

Tabel 1 Overzicht van bronmateriaal voor de actualisatie van de Geomorfologische Kaart van Nederland.

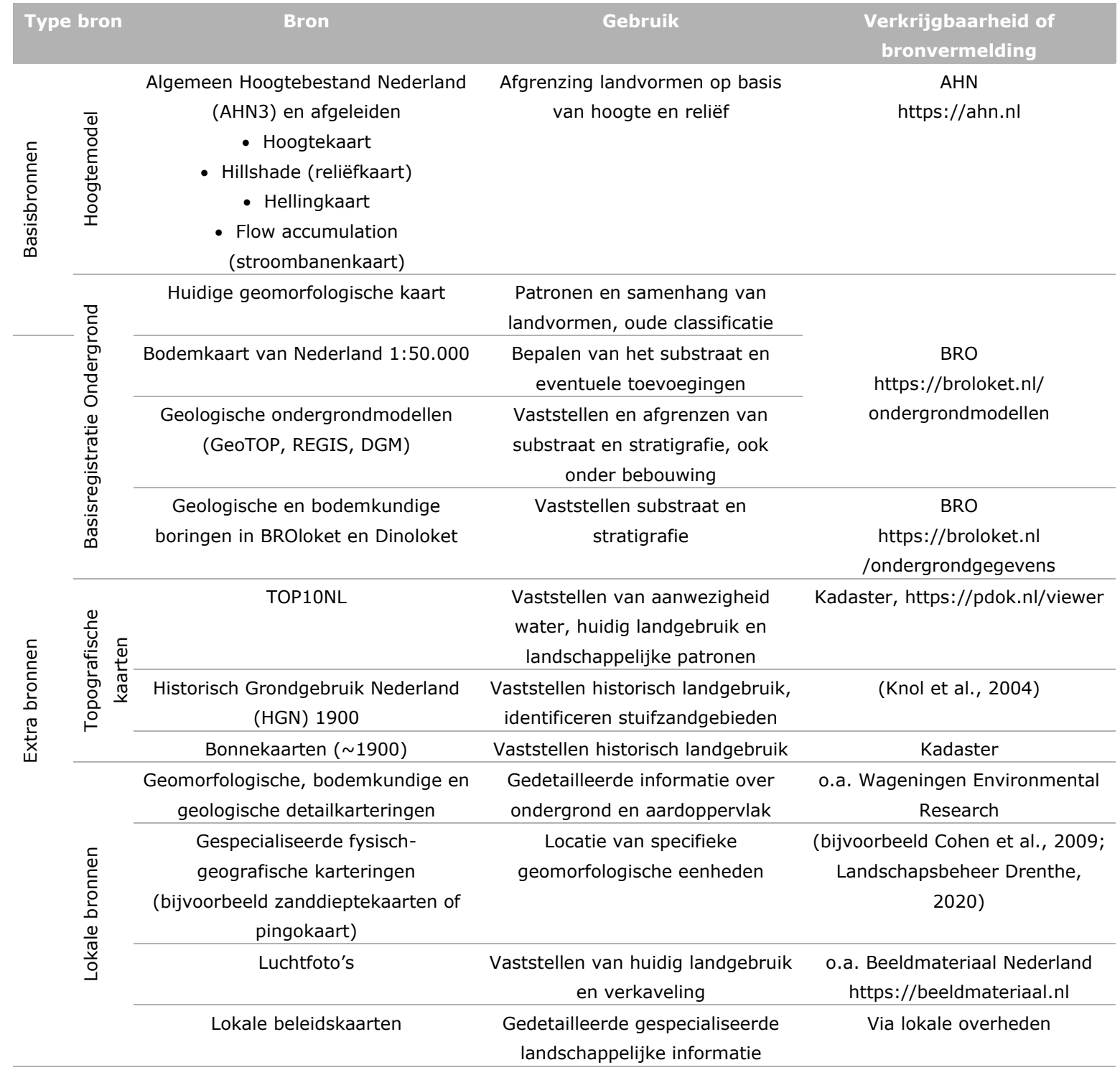




\subsection{Voorbereiding op het karteren}

\subsubsection{Theoretisch kader}

Als voorbereiding op het actualiserend karteren is een gedegen theoretische kennis van de ondergrond, geomorfologie en (historisch) landgebruik van het studiegebied nodig. Hiervoor kunnen bijvoorbeeld de relevante hoofdstukken in boeken over het Nederlandse landschap en ondergrond gelezen worden om bekend te worden met landschapstypen, -genese en -vormen. Voorbeelden van deze boeken zijn Landschappen van Nederland (Jongmans et al., 2013) en De vorming van het land (Stouthamer et al., 2020). Ook kan de huidige geomorfologische kaart bestudeerd worden om de ruimtelijke ligging van de landvormen te herkennen.

Het doel is het ontwikkelen van een conceptueel begrip van de geomorfologische eenheden en hun genese in het studiegebied. Dit kan bijvoorbeeld door een lijst te maken met de te verwachten geomorfologische eenheden in het studiegebied, het schetsen van landschapsgenese en landschapstype (geologische setting, fysisch-geografische regio) en een globale inschatting te maken van de verdeling en oppervlakte van de verschillende geomorfologische eenheden in het landschap.

\subsubsection{Legendaopbouw}

Naast het theoretisch kader moet de karteerder bekend zijn met de opbouw van de legenda van de geomorfologische kaart. Sinds 2017 wordt er een nieuwe legenda gehanteerd. Deze legenda is vastgelegd in de catalogus van de Geomorfologische kaart in de BRO (BRO, 2019) en in te zien via https://legendageomorfologie.wur.nl. In de nieuwe legenda is het aantal specifieke geomorfologische eenheden teruggebracht tot een kleiner aantal algemenere eenheden. Hierdoor is een uniformer kaartbeeld ontstaan, dat beter te begrijpen is. Er is nog een aantal restanten uit de oude legenda aanwezig, zoals complexe vormen, waarvan we vermoeden dat die in de komende jaren uitgefaseerd kunnen worden bij actualisaties door het beschikbaar komen van gedetailleerdere databronnen.

De legenda van de Geomorfologische Kaart van Nederland is hiërarchisch opgebouwd. De verschillende lagen geven informatie over bijvoorbeeld de vorm, genese en het reliëf van de landschapseenheid. Deze staan uitgebreid beschreven in de online legenda. De indeling van de legenda is als volgt:

1. Landvormgroep

a. Vormgroep: Onderscheiden van landvormen op basis van de uiterlijke kenmerken.

i. A-H: individueel te onderscheiden landvormen die uitsteken in het landschap (positieve vormen).

ii. L: complexe landvormen, die met de geldende gegevensbasis niet individueel gekarteerd kunnen worden.

iii. $M$ : vlakten, neutrale landvormen met weinig reliëf.

iv. N, R: individueel te onderscheiden landvormen die verzonken zijn in het landschap (negatieve vormen).

2. Landvormsubgroep

a. Genese: tien factoren die beschrijven onder welke omstandigheden, gelinkt aan geologische tijdsperiode, en door welk type processen de landvorm is gevormd.

b. Subgroepnummer: verdere onderverdeling van combinaties van landvormgroepen en geneses.

3. Landvormeenheid

a. Reliëf: Classificatie van de verticale dimensie van het landschap.

v. Er is een onderscheid in classificatie voor dalvormen en voor alle andere vormen.

vi. Classificatie is op basis van helling, hoogteverschil met de omgeving, verhang en maximaal verval (dalvormen).

\section{b. Toevoeging:}

vii. Toevoeging bedekking: aanvullende informatie over afwijkende sedimentpakketten boven op de vorm die van invloed is op de uiterlijke reliëfkenmerken van de vorm, zoals de aanwezigheid van stuifzand, oud bouwlanddek of overstromingsafzettingen. 
viii. Toevoeging reliëf: aanvullende informatie over het reliëf, die niet in de reliëfcode is opgenomen, maar die wel typerend is voor het kaartbeeld.

c. Actief proces: toevoeging om aan te geven of de geomorfologische processen die de vorm hebben gemaakt, de vorm nog steeds actief beïnvloeden.

\subsection{Stappenplan digitaal karteren}

Het huidige actualiseren van de Geomorfologische kaart (kartering Nieuwe Stijl) van een regio gebeurt in een aantal stappen. Deze staan hieronder en worden in Figuur 1 uitgelegd.

Eerst wordt de te actualiseren regio geselecteerd. De grootte van het gebied dat geactualiseerd gaat worden, hangt af van de beschikbare capaciteit van de karteerders en de te verwachten aanpassingen in de kaart. Gemiddeld kan er 20-30 km² per dag geactualiseerd worden. De criteria voor het selecteren van een regio die gekarteerd gaat worden, zijn:

1. De geomorfologische kaart van de regio moet grotendeels nog niet geactualiseerd zijn;

2. De regio sluit bij voorkeur aan bij eerder geactualiseerde regio's en/of bevat secties die al eerder geactualiseerd zijn in een andere context;

3. Er wordt voorrang gegeven aan regio's waar de geomorfologische kaart in grote mate afwijkt van hoogtekaarten en het werkelijke fysieke landschap.

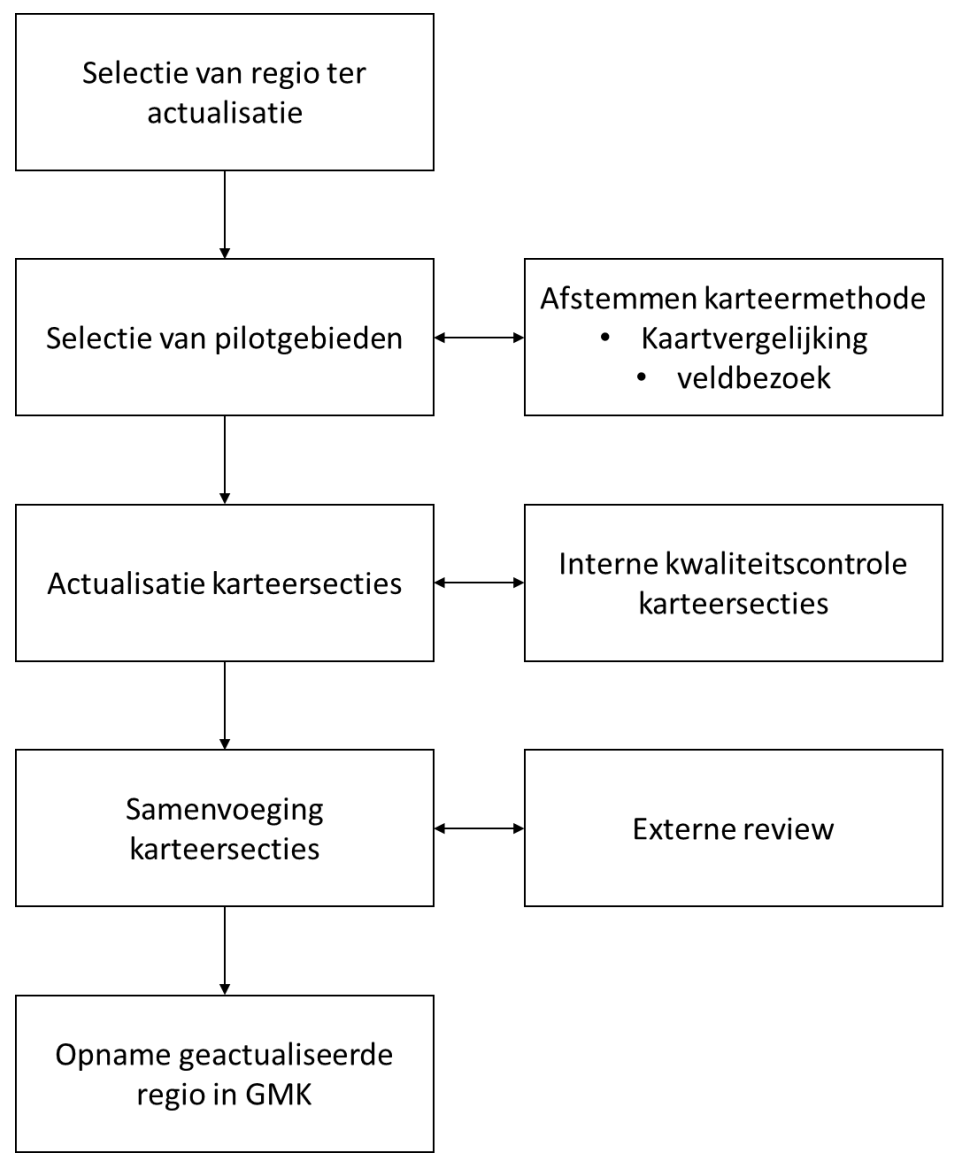

Figuur 1 Workflow voor het actualiseren van de geomorfologische kaart.

De te actualiseren regio wordt opgedeeld in verschillende karteersecties. Deze secties zijn behapbare gebieden die door één karteerder gekarteerd worden. De karteersecties worden afgegrensd langs natuurlijke grenzen in het landschap of, indien de secties te groot worden, volgens een regelmatig grid (Figuur 2). 
Binnen de te actualiseren regio wordt gekeken naar pilotgebieden die representatief zijn voor de regio. Dit kunnen ook kleine gebieden zijn die al eerder zijn geactualiseerd. In deze gebieden worden de afgrenzing en classificatie van de verschillende landvormen en de karteermethode afgestemd tussen de verschillende karteerders door een veldbezoek en door elke karteerder hetzelfde pilotgebied te laten karteren. Voor het vergelijken van de karteringen wordt de kaartvergelijkingsmethode gebruikt zoals beschreven in paragraaf 3.1.

Daarna worden per karteersectie handmatig de landvormen ingetekend in een GIS-omgeving. Het karteren kan op verschillende manieren, bijvoorbeeld:

- Door het aanpassen van de grenzen van de huidige geomorfologische kaart en het intekenen van missende vormen conform de legenda.

- Door alle vormen handmatig opnieuw in te tekenen in twee lege kaartbladen. In één kaartblad worden de regionale vormen getekend, in het andere kaartblad de lokale vormen die de grotere vormen bedekken, doorkruisen, insnijden of afwisselen. Deze twee kaartbladen worden later samengevoegd.

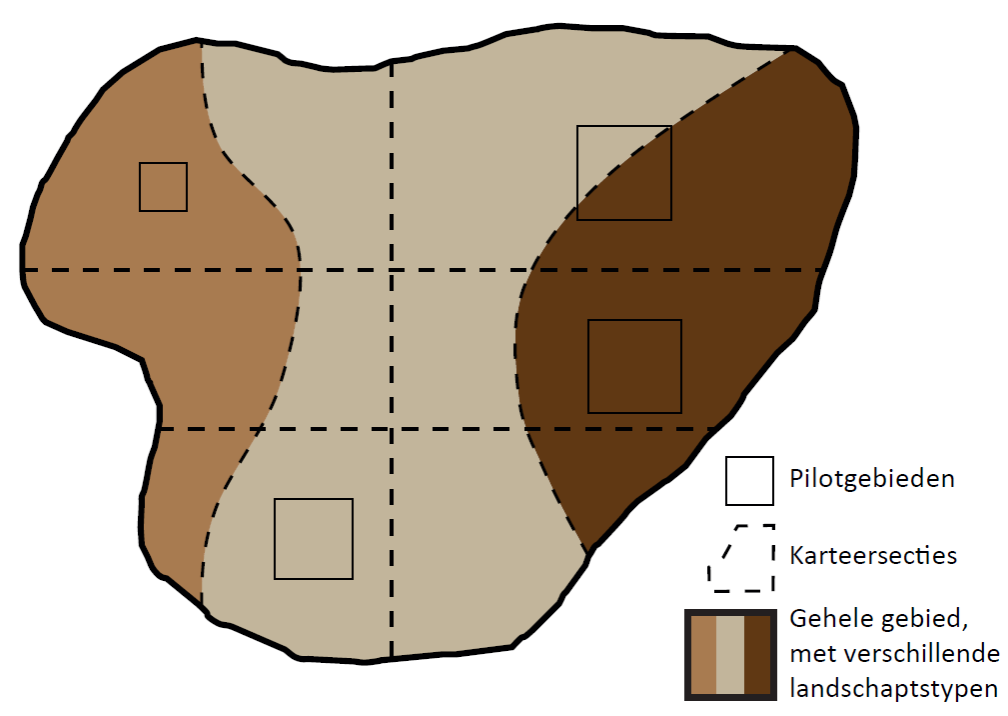

Figuur 2 De verschillende opdelingen van de te actualiseren regio, zoals gebruikt in het stappenplan voor het karteren. De karteersecties volgen de grenzen van de verschillende landschapstypen.

Het handmatig karteren wordt ondersteund door het gebruik van extra bronnen of andere methoden waarmee landvormen geïdentificeerd of geclassificeerd kunnen worden, zoals beschreven in paragraaf 2.1. Bij het karteren worden de keuzes die de karteerder maakt voor het identificeren en afgrenzen van vormen bijgehouden. Het classificeren van de landvormen volgens de legenda kan simultaan of na het intekenen van de vormen gebeuren.

Zodra alle karteersecties zijn geactualiseerd, worden deze op elkaar afgestemd en samengevoegd. Indien nodig kan er nog een veldbezoek uitgevoerd worden om landvormen met onduidelijke classificatie te controleren. Daarnaast kan er aan de hand van de veldwaarnemingen nog eens kritisch over de ontstaanswijze van het landschap nagedacht worden indien de bevindingen niet aansluiten bij de verwachtingen. Eventuele nieuwe inzichten worden dan verwerkt in de actualisaties. Digitale data zijn hiervoor niet altijd toereikend, omdat deze niet altijd beschikbaar zijn op de gewenste locaties en met het gewenste detailniveau in de beschrijvingen. 

De kwaliteit van de Geomorfologische kaart van Nederland wordt op verschillende manieren gewaarborgd. Dit wordt gedaan door afstemming van de karteermethode, een interne kwaliteitscontrole tijdens het karteren en een externe review na afronding van de actualisaties.

\subsection{Procedure voor afstemming karteermethode}

Het actualiseren van de geomorfologische kaart wordt gedaan door een team van geomorfologen binnen Wageningen Environmental Research. Ook al is iedereen bekend met het Nederlandse landschap, de legenda van de geomorfologische kaart en de manier van actualiseren, dan kan het toch zijn dat er verschillen in de actualisaties te zien zijn als gevolg van verschillen in ervaring, manier van het landschap lezen en prioriteren van bepaalde landvormen. (Zie ook hoofdstuk 4 voor een voorbeeld.) Om te zorgen dat iedereen zo veel mogelijk op dezelfde lijn zit tijdens het actualiseren, is er in 2020 een procedure ontwikkeld om verschillende karteringen te vergelijken, zodat grote verschillen in interpretatie en afgrenzing van vormen geïdentificeerd kunnen worden. Deze procedure beschrijven we in deze paragraaf en zal bij toekomstige actualisaties gebruikt worden in de beginfase van een actualisatieslag (zie ook paragraaf 2.3). Door in de beginfase de karteermethodes op elkaar af te stemmen, zal het uiteindelijke product uniformer van kwaliteit zijn. De procedure is ontwikkeld, getoetst en gereviewd in twee pilotgebieden in Zeeland en op de Utrechtse Heuvelrug. De resultaten van deze pilotgebieden staan beschreven in hoofdstuk 4. In deze paragraaf bespreken we de procedure zelf. De procedure is opgezet in samenwerking met geomorfologen van Wageningen Environmental Research, Wageningen University, Rijksuniversiteit Groningen en Universiteit Utrecht.

Het afstemmen van de karteermethode zal gebeuren in pilotgebieden van ongeveer $25 \mathrm{~km}^{2}$, welke in enkele dagen te karteren zijn (Figuur 2). De pilotgebieden worden zo geselecteerd, dat de verwachte geomorfologische variatie in een te actualiseren regio zo goed mogelijk vertegenwoordigd is. Elke geomorfoloog maakt zijn eigen kartering van het pilotgebied. Iedereen heeft beschikking over dezelfde basisbronnen en extra bronnen, zoals vermeld in paragraaf 2.1. Verder staat het iedereen vrij om overige data en kaartmateriaal te gebruiken naar eigen inzicht en ervaring.

Door de verschillende karteringen onderling te vergelijken, kan er getoetst worden in welke mate deze wel of niet overeenkomen en waar dus de karteermethode beter afgestemd moet worden tussen de verschillende geomorfologen. De overeenkomsten tussen verschillende kaartbladen kunnen op verschillende aspecten getoetst worden: op de compleetheid en het detailniveau van de kaart, de afgrenzing van de landvormen en de classificatie van de landvormen. Deze aspecten kunnen per onderdeel van de legenda getoetst worden, bijvoorbeeld voor het reliëf, de vormgroep, de genese en de vormsubgroep. Wij hebben gekozen voor een kwantitatieve methode voor het vergelijken van de verschillende kaarten. De geselecteerde methode neemt alle bovengenoemde aspecten mee om te kwantificeren wat de overeenkomst is tussen de individuele karteringen. De volgende stappen worden doorlopen (Figuur 3):

1. De vectorbestanden worden omgezet naar een rasterbestand met een celgrootte van 10*10 meter, uitgelijnd op de gridcellen van het AHN. Voor elk legendaonderdeel wordt er een aparte rasterkaart gemaakt. De rasterkaarten van iedere variabele worden daarna over elkaar heen gelegd.

2. Om te bepalen welke klasse het meest is gekarteerd, wordt voor elke locatie bepaald welke klasse het meest voorkomt. Indien er meerdere klassen gelijk aanwezig zijn, wordt er willekeurig één gekozen uit de meest voorkomende klassen. Deze stap levert een kaart op met de meest waarschijnlijke klasse op basis van de vijf inputkaarten. 
3. De overeenkomst tussen de kaarten wordt bepaald door voor elke cel de frequentie van de meest voorkomende klasse te vergelijken met het aantal kaarten. Dit wordt gedaan met de volgende formule: overeenkomst $=\frac{\text { frequentie-1 }}{\text { aantal } \text { kaarten }-1}$. Deze formule geeft waarden tussen 0 en 1 , waarbij 0 aangeeft dat er geen overeenkomst is en 1 aangeeft dat er volledige overeenkomst is. Deze stap levert een kaart op met de mate van overeenkomst tussen de vijf verschillende kaarten.

4. Het gemiddelde van de kaarten uit stap 3 bepaalt de algehele overeenkomst per variabele. Deze waarde kan gezien worden als de kwaliteit van de geomorfologische kaart.

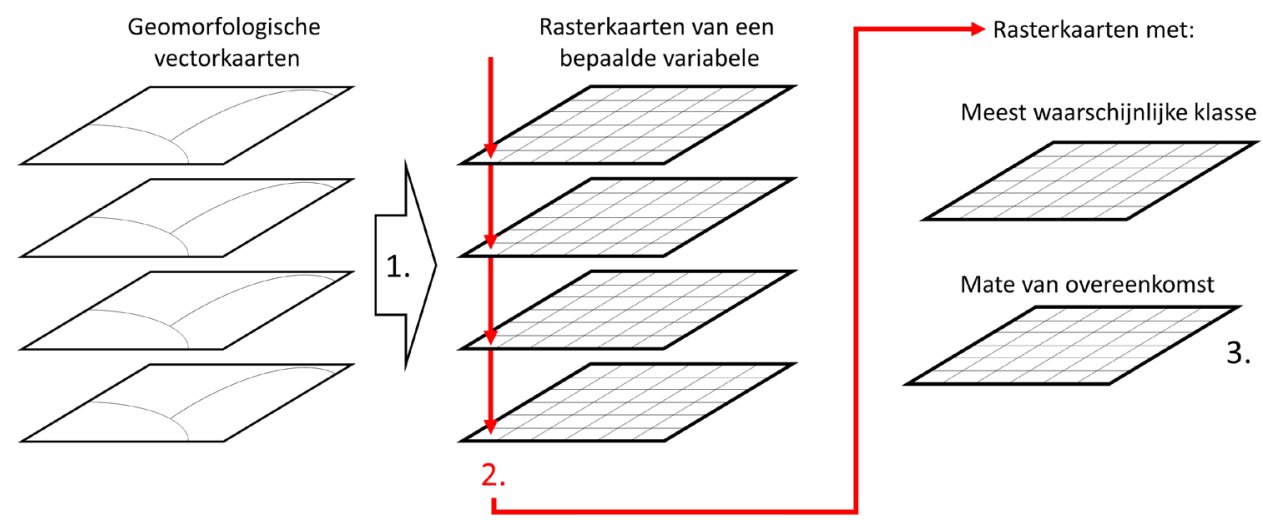

Figuur 3 Workflow voor de onderlinge vergelijking van karteringen, met als uitkomst een kaart met de meest waarschijnlijke klasse en de mate van overeenkomst.

Deze procedure helpt de verschillen in de kaarten te visualiseren en kwantificeren en daarmee aan te geven welke aspecten beter op elkaar afgestemd moeten worden. Hierbij kan gedacht worden aan het gebruik van verschillende databronnen, manier van afgrenzen van vormen, detailniveau van de karteringen en interpretatie van de geomorfologische eenheden. Voor de laatste stap kunnen de geomorfologische eenheden met de minste overeenkomst in het veld bezocht worden om door middel van boringen en andere veldwaarnemingen te bepalen welke afgrenzing en classificatie juist zijn. Hoofdstuk 4 laat een aantal voorbeelden zien van de verschillen die voor kunnen komen.

De afstemming tussen karteermethode en interpretatie van het landschap vormt hiermee de basis voor de verdere actualisatie van de geselecteerde regio.

\subsection{Interne kwaliteitscontrole}

$\mathrm{Na}$ het afstemmen van de karteermethode in de pilotgebieden worden de karteersecties in de regio geactualiseerd. In deze paragraaf beschrijven we de interne kwaliteitscontrole die wordt uitgevoerd tijdens het actualiseren en bij het samenvoegen van verschillende karteersecties. De interne kwaliteitscontrole is tweedelig. Ten eerste wordt de inhoud van de kaart gecontroleerd op volledigheid en consistentie. Ten tweede wordt er een technische check uitgevoerd om de volledigheid van de kaart en legendaeenheden te toetsen.

Inhoudelijk wordt de geactualiseerde kaart gecontroleerd op gebiedsvreemde classificaties. Hierbij wordt gekeken of er afwijkende vormgroepen, geneses en reliëfcodes voorkomen. Indien dit het geval is, worden deze gecontroleerd op correctheid door onderling overleg en eventueel een veldbezoek en daarna, indien nodig, aangepast. Bij het integreren van verschillende karteersecties wordt gecontroleerd of de kaartbladen aan de randen aansluiten en of de geomorfologische eenheden dezelfde classificatie hebben.

De technische controle van de kaartbladen wordt in een GIS-programma uitgevoerd. Deze controle wordt eenmalig over het volledige afgeronde geactualiseerde regio uitgevoerd. Hierbij worden de volgende zaken gecontroleerd:

- Harmonisatie van attributen; 
- Dissolve op basis van volledige geomorfologische code om complete vormen te krijgen;

- Join met de domeinlijsten waarin de beschrijvingen van de geomorfologische codes staan;

- Repareren van Topology-fouten:

- Gaps tussen polygonen;

- Overlaps tussen polygonen.

- Gelijktrekken attribuutnamen tussen geactualiseerd bestand en Geomorfologische kaart van Nederland;

- Geactualiseerd bestand invoegen in de Geomorfologische kaart van Nederland:

- Invoegen kaartblad;

- Verwijderen van slivers die ontstaan zijn aan de randen;

- Samenvoegen van landvormen uit de actualisatie en omliggende vormen.

\subsection{Externe kwaliteitscontrole}

$\mathrm{Na}$ actualisatie van de gehele regio wordt de nieuwe kaart voorgelegd aan een gebiedsexpert voor een externe review. De gebiedsexpert zal vanuit zijn expertise de kaart beoordelen op de volgende criteria, waarbij de volgende vragen gesteld kunnen worden:

1. Consistentie van het kaartblad

a. Past de kaart bij de geomorfologische kennis die de reviewer van de regio heeft?

b. Klopt het genetische verhaal van het kaartblad?

c. Hebben alle geomorfologische eenheden de juiste ligging ten opzichte van elkaar?

d. Is de legenda van de geomorfologische kaart van Nederland toereikend voor de geomorfologische situatie in de regio?

2. Mate van verandering ten opzichte van de vorige kaart

a. Doen de aanpassingen in de kaart recht aan het werkelijke landschap?

b. Sluit de geactualiseerde kaart goed aan op het AHN?

c. Zijn de keuzes die de karteerders hebben gemaakt tijdens het karteren correct?

d. Zijn de actualisaties in de karteersecties goed op elkaar afgestemd?

\section{$3.4 \quad$ Afronding}

Met de stappen die beschreven staan in dit hoofdstuk wordt de kwaliteit van het actualisatieproces en de geomorfologische kaart van begin tot eind gewaarborgd. Hiermee zal er een consistente, geactualiseerde geomorfologische kaart opgeleverd worden die voldoet aan de kwaliteitseisen en het nauwkeurigheidsniveau die gevraagd worden vanuit de gebruiker.

Nadat het geactualiseerde kaartblad is opgenomen in de geomorfologische kaart, wordt deze opgeleverd aan de BRO. Het voornemen is om dit eens per jaar te doen. Nadat de kaart verwerkt is, komt deze beschikbaar via https://broloket.nl/ondergrondmodellen, waar naast de geomorfologische kaart ook andere ondergrondmodellen in te zien zijn. Hiermee is het stadium van actualisatie van de regio afgerond.

Ondanks de gedegen kwaliteitscontrole kan het zijn dat er onjuistheden of onduidelijkheden in de kaart zitten. Deze kunnen via het BROloket gemeld worden, waarna er een reparatie aan de kaart gedaan zal worden. Daarnaast zal de kaart regulier onderhouden gaan worden in gebieden waar dat nodig is. Deze onderhoudsfase begint nadat de gehele kaart geactualiseerd is. 



\section{$4 \quad$ Kwaliteitscontrole in de praktijk}

Voor de ontwikkeling van de kwaliteitsprocedure zijn er twee pilotgebieden gekarteerd door geomorfologen van binnen en van buiten Wageningen Environmental Research. De ontwikkelde procedure staat beschreven in paragraaf 3.1. Dit hoofdstuk bespreekt de resultaten van deze studie, identificeert aandachtspunten voor de kwaliteitscontrole van de Geomorfologische kaart van Nederland en geeft een kwaliteitsindicatie aan de actualisaties van de pilotgebieden.

De pilotgebieden liggen in recentelijk geactualiseerde regio's, namelijk het zeekleilandschap van Zeeland, geactualiseerd in 2012, en het stuwwallandschap van de Utrechtse Heuvelrug, geactualiseerd in 2019.

De vakexperts hebben elk een kartering gemaakt van beide pilotgebieden. Deze zijn onderling vergeleken en vergeleken met de oude en geactualiseerde geomorfologische kaart (Tabel 2, Figuur 4). Per pilotgebied waren vier kaarten ontwikkeld door de vakexperts. Samen met de oude en geactualiseerde geomorfologische kaart leverde dat zes kaarten per pilotgebied op voor onderlinge vergelijking. We hebben de kaarten zowel visueel (paragraaf 4.1) als kwantitatief vergeleken (paragraaf 4.2).

Tabel 2 Overzicht van vergeleken kaartbladen van de bijdragen van het team van geomorfologen en uit de oude en geactualiseerde geomorfologische kaart. Bij de geactualiseerde geomorfologische kaart wordt aangegeven wie de actualisatie heeft uitgevoerd.

\begin{tabular}{|c|c|c|c|c|}
\hline Bron of affiliatie & Naam & afkorting & Utrechtse Heuvelrug & Zeeland \\
\hline WENR & Gilbert Maas & GM & $x$ & \\
\hline WUR & Jasper Candel & $\mathrm{JC}$ & $x$ & $x$ \\
\hline RUG & Erik Meijles & EWM & $x$ & $x$ \\
\hline $\begin{array}{l}\text { Geomorfologische } \\
\text { kaart van Nederland }\end{array}$ & Geactualiseerd & new & $X(M M)$ & $X(G M)$ \\
\hline
\end{tabular}

\subsection{Visuele vergelijking karteringen}

De verschillende karteringen van de Utrechtse Heuvelrug laten grotendeels dezelfde eenheden zien, maar de verspreiding verschilt. De regionale vormen, of macrovormen, laten allemaal hetzelfde patroon zien; met de stuwwal (B11) in het midden, omringd door de uitspoelwaaiers en -vlaktes (G11, M11), gordeldekzand (L52) en stuifzand (M54, L54). Deze vormen worden doorsneden, afgedekt of afgewisseld met lokale vormen, of microvormen, zoals stuwwalplateaus (D11), droge dalen (R21) en landduinen (B58). Daarnaast zijn er ook een aantal vormen die niet door iedereen zijn gekarteerd, zoals laagten zonder randwal (N51), smeltwaterheuvels en -ruggen (B15, B16) en groeves en afgravingen (N91, N94).

Voor Zeeland komen er minder verschillende geomorfologische eenheden voor in het studiegebied. De verspreiding van deze vormen is echter zeer gevarieerd ingetekend. In het midden wisselen vlakten en welvingen van plaatselijke gemoerde getij-afzettingen (L72, M71) elkaar af. Daaromheen zijn vlakten van getij-afzettingen (M71) of getij-inversieruggen (B71) ingetekend. De ligging van de grens tussen deze twee vormen verschil verschilt per kaart. Elke kaart bevat de rechthoekige getijinversieruggen in het midden van de kaart, maar het verschilt per kaart of daar getij-kreekbeddingen 
(R71) in getekend zijn. Op twee kaarten zijn hoogwatervluchtplaatsen (B91) ingetekend, welke momenteel deels onder bebouwing liggen.

Wat opvalt aan de karteringen door WENR-medewerkers en externe vakexperts, is dat de WENRmedewerkers meer lokale vormen intekenen en de andere vormen met meer detail afgrenzen. Voorbeelden zijn het voorkomen van stuifzandvlaktes (M54) in stuifzandgebieden op de Utrechtse Heuvelrug of het aantal getij-kreekbeddingen (R71) ingetekend in Zeeland. Dit komt waarschijnlijk door hun ervaring met geomorfologisch karteren in een GIS-programma en hun bekendheid met de legenda van de geomorfologische kaart.

Een ander opvallend verschil zit in de keuze voor de dominante geomorfologische eenheid welke te zien is in het kaartblad. Bij de kaart van EWM op de Utrechtse Heuvelrug is er bijvoorbeeld gekozen om voornamelijk de uitspoelwaaier (G11) te laten zien aan de westkant van de stuwwal in plaats van de droge dalen die deze doorsnijden. Bij de kaart van GM is het stuifzandgebied (L54, M54) aan de westkant van de stuwwal veel kleiner ingetekend, maar heeft de omliggende uitspoelvlakte (M11) wel een toevoeging ' $s$ ' gekregen, wat aangeeft dat er stuifzand aanwezig is op de vorm. Hetzelfde geldt voor stuifzand op de stuwwal, die bij de kaart van GM ook gekarteerd is met een toevoeging, terwijl de andere kaarten het stuifzand als dominante vorm hebben ingetekend.

Ter controle van de correctheid van de karteringen van de Utrechtse heuvelrug heeft het team karteerders een veldcontrole uitgevoerd. Hierbij is een aantal landvormen in meer detail onderzocht door middel van veldwaarnemingen. Op basis van het substraat en de mate van bodemvorming konden per locatie de genese en leeftijd van de landvorm ingeschat worden. Ook is er voor een aantal vormen bepaald of een eventuele stuifzandbedekking als hoofdvorm gekarteerd zou worden (L54) of als toevoeging opgenomen zou worden. Deze informatie is verwerkt tot een consensuskaart door aanpassingen in de classificatie te verwerken in het meest gedetailleerde kaartblad van GM (Figuur 5).

De veldcontrole heeft nieuwe inzichten gegeven in de distributie en morfologie van stuif- en dekzanden. Waar de meeste karteerders het gebied ten oosten van de stuwwal als stuifzand hadden gekarteerd op basis van de morfologie en bronbestanden (Figuur 6), heeft de veldcontrole aangetoond dat het hier gaat om zeer hoge en steile dekzandduinen. Deze duinen bevatten namelijk een volledig ontwikkelde bodem, die zich nog niet gevormd zou kunnen hebben in het veel jongere stuifzand. Ten westen van de stuwwal ligt een aantal kleine ruggen (B16) bestaande uit grof grind, die zijn achtergebleven na erosie van het fijnere materiaal dat eromheen lag. Deze ruggen waren waarschijnlijk grindige lagen in de ondergrond die gestuwd zijn door het landijs in de een-na-laatste ijstijd. Ten westen van de stuwwal is ook veel minder stuifzand gekarteerd als dominante landvormsubgroep in vergelijking met de verschillende karteringen. Op deze landvormen is wel stuifzand aanwezig (toevoeging 's'), maar het stuifzand is niet de dominante landvorm. Dat zijn de onderliggende waaiers en vlaktes van smeltwaterafzettingen (G11 en M12). Deze nieuwe inzichten en karteerhandvatten worden verwerkt in het kaartblad van de gehele geomorfologische kaart van de Utrechtse Heuvelrug voordat deze gepubliceerd wordt. 

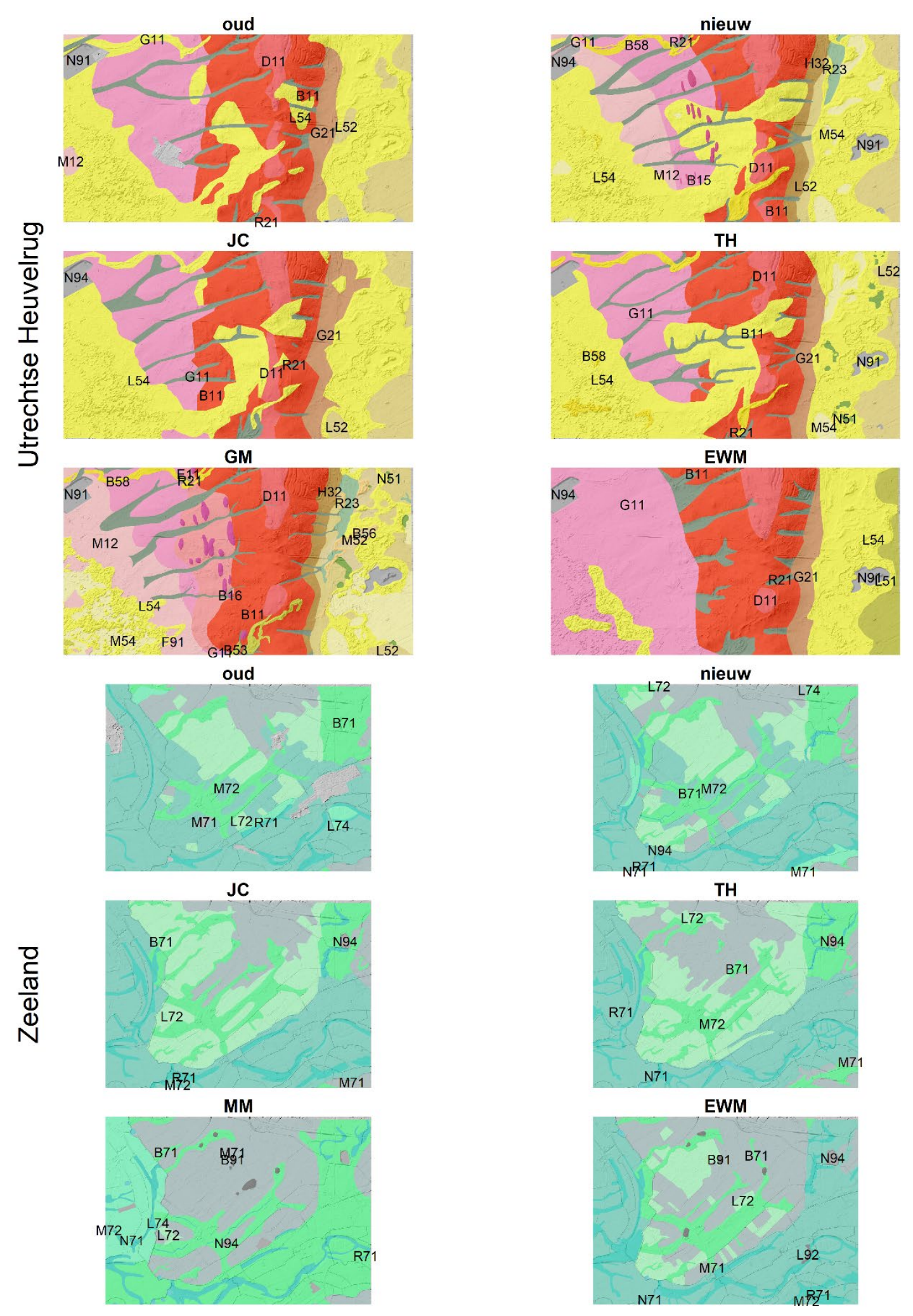

Figuur 4 Overzicht van zes verschillende karteringen van studiegebied Utrechtse Heuvelrug (boven) en Zeeland (onder). De karteringen bevatten de oude en geactualiseerde geomorfologische kaart, en vier individuele karteringen door het team van geomorfologen (Tabel 2). Voor de beschrijvingen van de geomorfologische eenheden verwijzen we naar de online legenda. 


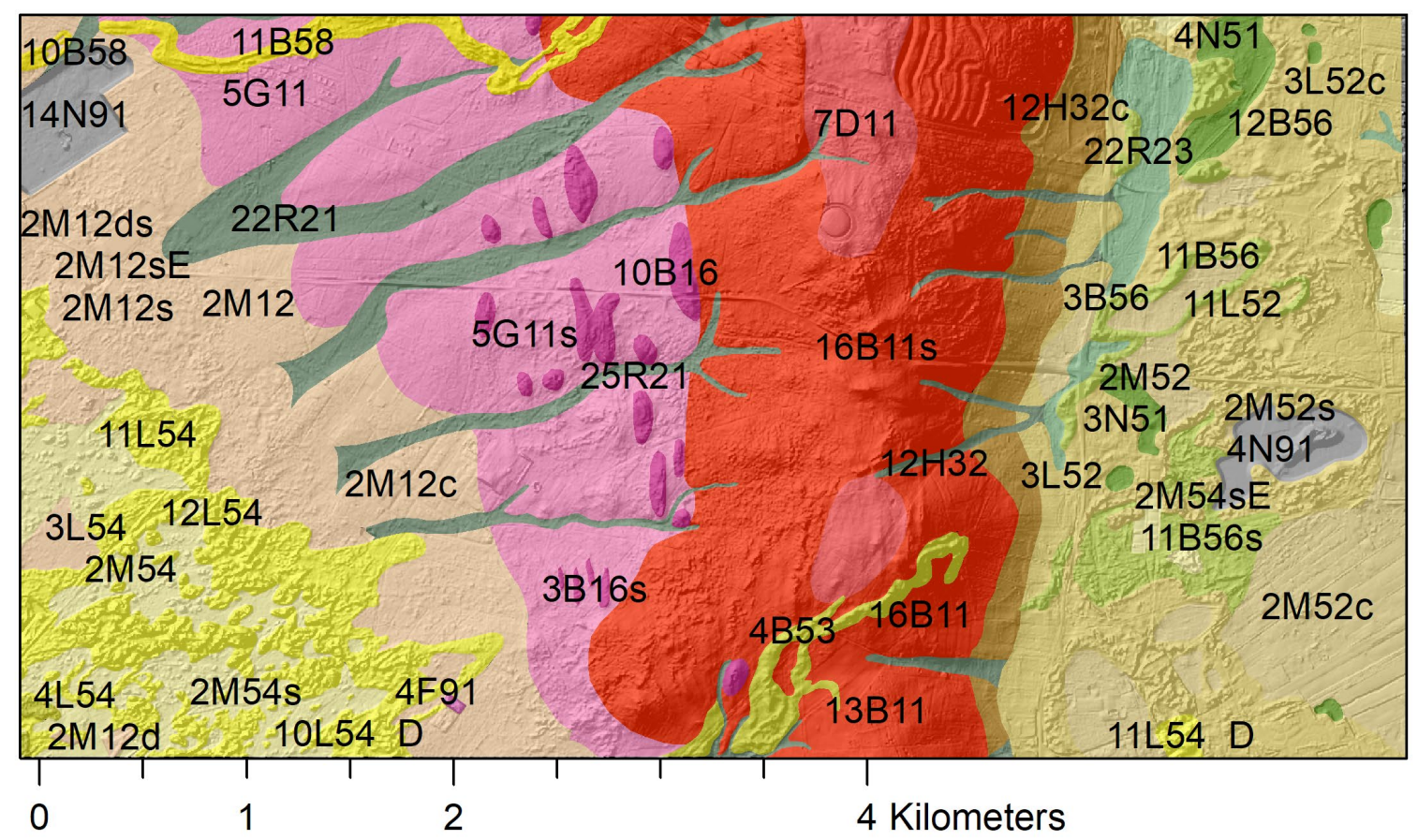

\section{Legenda}

B: Geïsoleerde heuvels, heuvelruggen en dijken

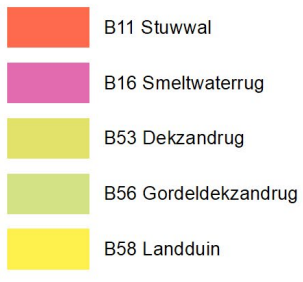

D: Plateaus

D11 Stuwwalplateau

F: Plateau-achtige vormen

F91 Plateau-achtige storthoop, opgespoten terrein of kunstmatig eiland

G: Waaiervormige glooiingen

G11 Smeltwaterwaaier

$\mathrm{H}$ : Niet-waaiervormige glooiingen

H32 Glooiing van hellingafspoelingen
L: Heuvels en heuvelruggen met bijbehorende vlakten en laagten

L52 Gordeldekzandwelvingen

L54 Landduinen met bijbehorende vlakten en laagten

\section{M: Vlakten}

M12 Vlakte van smeltwaterafzettingen

M52 Gordeldekzandvlakte

M54 Stuifzandvlakte

\section{$\mathrm{N}$ : Niet- dalvormige laagten}

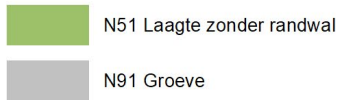

\section{R: Dalen}

R21 Droogdal

R23 Dalvormige laagte

Figuur 5 De consensuskaart van studiegebied Utrechtse Heuvelrug. Deze kaart is samengesteld na de veldcontrole, waarin de correctheid van een aantal classificaties is gecontroleerd. 


\subsection{Samengestelde kaarten en karteerovereenkomst}

Deze paragraaf geeft een kwantitatieve vergelijking van de geproduceerde kaarten door het produceren van samengestelde kaarten volgens de procedure beschreven in paragraaf 3.1. Figuur 6 laat deze samengestelde kaarten zien van de vormsubgroepen in beide gebieden. Naast de samengestelde kaart is ook de overeenkomstkaart weergegeven. Deze laat zien in hoeverre de verschillende karteringen met elkaar overeenkomen, op een schaal van 0 tot 1 . Het laatste venster laat de gemiddelde overeenkomst per vorm zien.
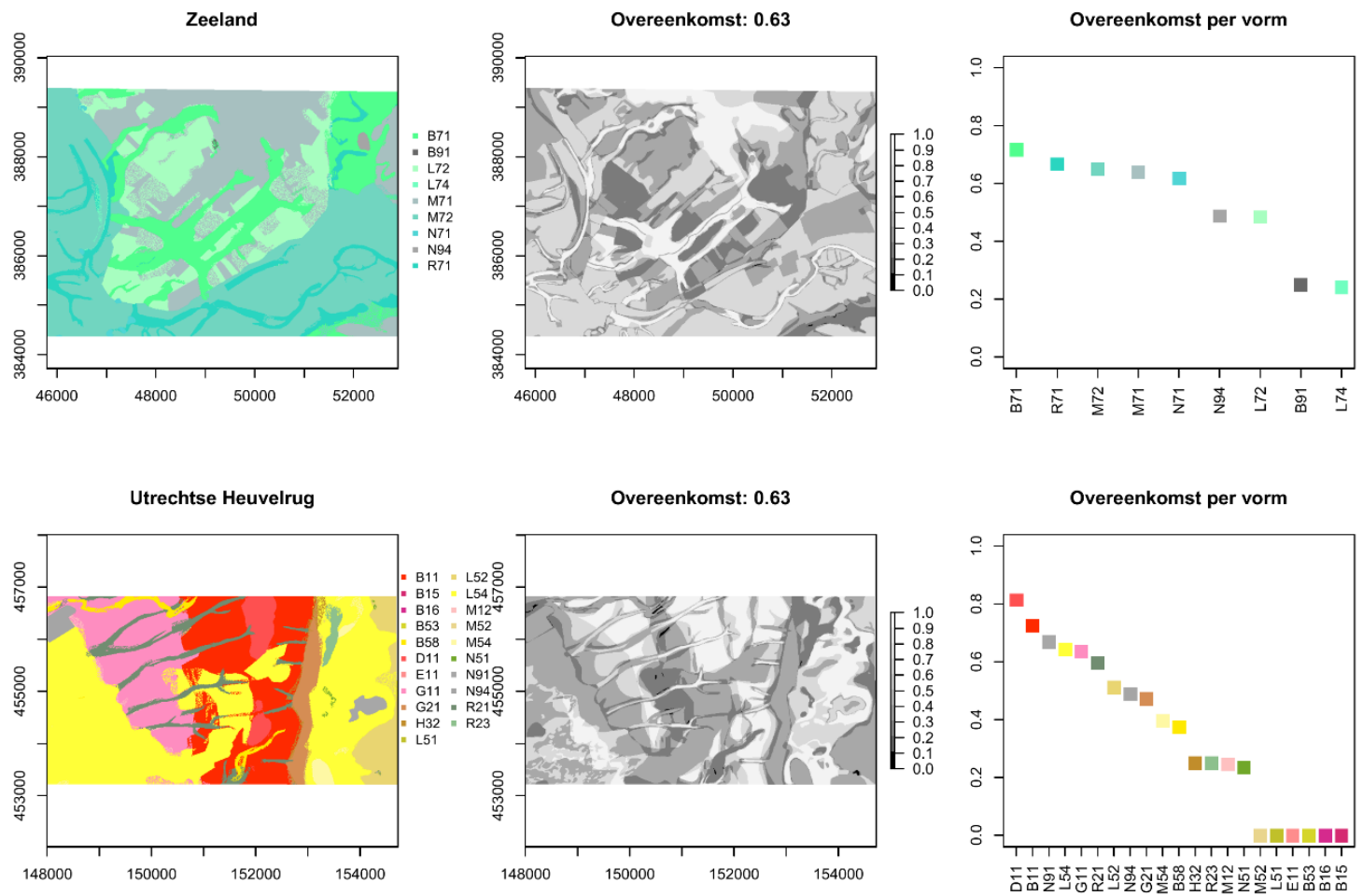

Figur 6 Samengestelde kaarten van de vormsubgroepen in beide studiegebieden. De vijf kaarten die hiervoor gebruikt zijn, zijn de geactualiseerde geomorfologische kaart en de vier kaarten gemaakt door individuele geomorfologen (Tabel 2). De linkerkolom laat de samengestelde kaart zien waarop de meest gekarteerde geomorfologische eenheid te zien is. De middenkolom laat de karteerovereenkomst tussen de kaarten zien. De rechterkolom laat de gemiddelde karteerovereenkomst per geomorfologische eenheid zien.

De vormen die de meeste overeenkomst vertonen, zijn regionale vormen die een groter gebied beslaan en lokale vormen die duidelijk in het landschap te zien zijn. Dit zijn bijvoorbeeld vlakten van getij-afzettingen (M72) en vlakten van plaatselijk gemoerde getij-afzettingen (M71) in Zeeland en stuwwal(plateaus) (B11, D11), smeltwaterwaaiers (G11) en complexen van landduinen (L54) op de Utrechtse Heuvelrug. Deze vormen beslaan een groot oppervlak en bepalen daarmee het regionale kaartbeeld. Door hun grote oppervlak zijn deze eenheden niet het indicatiefst voor het toetsen van de karteerovereenkomst, omdat er relatief gezien weinig grenzen zijn voor het grote oppervlak op de kaart in vergelijking met kleinere vormen. Dit is goed te zien in de kaarten met overeenkomstwaarden, waar de grotere vormen een hoge overeenkomst midden in de vorm hebben. Aan de rand neemt de overeenkomst af. Voor kleinere lokale vormen zijn de onzekere randen relatief groot vergeleken met de regionale vormen, waardoor deze vormen vaak een lagere overeenkomst vertonen.

Uitgesproken lokale vormen, zoals de getij-inversieruggen (B71) en kreekbeddingen/zee-erosiegeulen (R71) in Zeeland en de groeves (N91) en de droge dalen (R21) op de Utrechtse Heuvelrug, zijn met 
hoge overeenkomst gekarteerd. Deze vormen hebben vaak scherpe grenzen (R71, N91) of komen veel voor (B71, R21), waardoor deze met meer nauwkeurigheid ingetekend kunnen worden.

Vormen die weinig overeenkomst vertonen, zijn vaak relatief klein zijn en/of komen weinig voor (bijvoorbeeld B15, B16 en B91). Deze vormen zijn niet door iedereen herkend als individuele vorm. Vormen waarvan de classificatie niet eenduidig is af te leiden uit de bronbestanden hebben ook een lagere overeenkomst (bijvoorbeeld L51, M52, B53, E11 en L74).

Tabel 3 Overeenkomst tussen de verschillende realisaties van de Geomorfologische kaart in de verschillende studiegebieden. De overeenkomstwaarden variëren van 0 (geen overeenkomst) tot 1 (complete overeenkomst).

\begin{tabular}{cccccc} 
Fysisch-geografische & Studiegebied & \multicolumn{5}{c}{ Overeenkomst } \\
\cline { 3 - 6 } regio & Reliëf & Vormgroep & Genese & Vormsubgroep & Gemiddeld \\
Hogere zandlandschap & $\begin{array}{c}\text { Utrechtse } \\
\text { Heuvelrug }\end{array}$ & 0.38 & 0.67 & 0.79 & 0.63 \\
\hline Zeekleilandschap & Zeeland & 0.51 & 0.66 & 0.97 & 0.63 \\
\hline
\end{tabular}

De karteerovereenkomsten kunnen gebruikt worden om een kwaliteitsindicatie aan de kaart te geven. In Tabel 3 zijn de karteerovereenkomsten van verschillende onderdelen van de legenda te zien. Hieruit is af te leiden dat de kaarten gemiddeld tussen de 60 en $70 \%$ overeenkomen, oftewel de vakexperts zijn het voor 60-70\% met elkaar eens en de rest kan verschillen door verschillen in interpretatie, karteertechniek, detailniveau en karteerkeuzes. De overeenkomst zal stijgen als de karteermethode afgestemd wordt voordat men begint met karteren (paragraaf 3.1), omdat er dan afspraken worden gemaakt over de kaartonderdelen waar een lage overeenkomst over is.

De verschillen zijn dus deels te verklaren door verschillende classificaties en afgrenzingen van vormen, maar ook door het detailniveau in de kaarten, zoals hierboven te zien is. De genese laat een hoge overeenkomst zien, omdat verschillende aangrenzende landvormen vaak dezelfde genese hebben. Daardoor wordt er geen onzekerheid geïntroduceerd voor de classificatie van genese aan de grenzen van deze vormen. Dit is met name het geval in Zeeland, waar het hele gebied een mariene genese heeft, op enkele antropogene vormen na. Dit kan natuurlijk anders zijn in gebieden waar veel verschillende geneses voorkomen. De reliëfclassificatie scoort in beide gebieden het laagst. Voor het bepalen van het reliëf zijn er richtlijnen opgesteld in de legenda, maar deze verschillen per type vorm. Ook is er veel lokale variatie in de reliëfklassen, afhankelijk van de grootte en het aantal landvormen. Deze twee factoren zorgen voor een lagere overeenkomst in reliëfklassen op de verschillende kaarten. Voor landvormen in reliëfrijk terrein, zoals op de Utrechtse Heuvelrug, is het mogelijk om de reliëfklasse automatisch te bepalen door middel van berekeningen met het AHN en diens afgeleide kaarten. Hierdoor kunnen de reliëfklassen eenduidiger geclassificeerd worden. Voor gebieden met weinig reliëf, zoals in Zeeland, werken deze berekeningen niet, omdat verstoringen in het terrein (zoals wegen en bebouwing) meer variatie in reliëf veroorzaken dan het landoppervlak zelf bevat.

Een hoge overeenkomst tussen de verschillende kaarten betekent niet per se dat de kaart ook goed bij de werkelijkheid aansluit. Het kan bijvoorbeeld zijn dat een bepaald patroon op de hoogtekaart geassocieerd wordt met een bepaalde vorm en genese, terwijl er in werkelijkheid een andere landvorm ligt. Een voorbeeld hiervan zijn de landduinen in het oosten van studiegebied Utrechtse Heuvelrug, waar alle karteerders jong stuifzand hadden gekarteerd, terwijl dit in werkelijk dekzand bleek te zijn. Ook kan het zijn dat de gebruikte bronbestanden foutieve informatie bevatten die zo in de geomorfologische kaart terechtkomen. Een goede afstemming van de karteermethode, met een gedegen interne en externe kwaliteitscontrole met onafhankelijke data en veldwaarnemingen (hoofdstuk 3 ) is dus van belang voor een juiste geomorfologische kartering van het landschap. 


\subsection{Conclusies}

Op basis van het beschikbare digitale bronmateriaal en kennis van het landschap tijdens het karteren, zijn in deze studie geomorfologische kaarten gemaakt die voor 60-70\% overeenstemming vertonen. Deze waarde hangt af van het detailniveau van de karteringen, karteerervaring en de plaatsing van diffuse grenzen tussen geomorfologische eenheden. Afstemming van karteermethode en classificatie zal de karteerovereenkomst tussen de verschillende kaarten vergroten en daarmee dus ook de kwaliteit van de actualisaties van de geomorfologische kaart verhogen.

De veldcontrole in de Utrechtse Heuvelrug heeft laten zien dat de werkelijkheid niet altijd overeenkomt met de gebruikte bronbestanden en kennis van de morfologie van het landschap. Een veldcontrole is daarom essentieel voor de kwaliteit en inzetbaarheid van de geomorfologische kaart en de algemene kennis van het ontstaan van het Nederlandse landschap.

\section{Reflectie van karteerders op het proces}

Naast het produceren van de verschillende kaarten hebben de karteerders ook een reflectie gegeven op het proces. Dit zijn de belangrijkste bevindingen:

- Het begrenzen van vormen is lastig, voornamelijk bij graduele grenzen. Het kwaliteitsdocument moet informatie bevatten over de onzekerheid van de grenzen. Daarnaast moet van tevoren afgestemd worden hoe vormen precies afgegrensd worden en aan welke landvormen prioriteit wordt gegeven bij het classificeren.

- Legendadefinities zijn niet altijd eenduidig en kunnen breder geïnterpreteerd worden.

- Gebieden met meer uitgesproken reliëf zijn makkelijker te karteren, doordat vormen beter te onderscheiden zijn

- De gebruikte brondata zijn vaak ook modellen of interpretaties van de werkelijkheid, waardoor fouten en subjectiviteiten uit deze bestanden makkelijk propageren in de geomorfologische kaart. De geomorfologische kaart gebruikt andere kaarten en modellen, zoals de bodemkaart en geoTOP als bronbestanden. Deze modellen maken op hun beurt ook gebruik van de geomorfologische kaart. $\mathrm{Er}$ moet voorkomen worden dat er zo cirkelredenaties in de classificatie van geomorfologische eenheden sluipt. Hier is ook raadpleging van onafhankelijke data voor nodig.

- De veldcontrole heeft de waarde van veldwerk laten zien. Bij karteren op basis van digitaal beschikbare data kunnen er snel fouten in de kaart en classificatie sluipen. De discussies in het veld helpen het inzicht in het landschap verbeteren. Dit kan tot meer detail op de uiteindelijke kaart leiden. Eén veldcontrole per kaartblad zou voldoende moeten zijn. Daarnaast levert zo'n velddag ook nieuwe kennisvragen over het ontstaan van het Nederlandse landschap op.

- Kaarten die met elkaar vergeleken worden kunnen veel overeenkomen, maar ze kunnen beide ver van de werkelijkheid afstaan. 



\section{Conclusies}

De actualisatie van de Geomorfologische kaart van Nederland is in een hogere versnelling gekomen met de opname in de BRO en door strengere kwaliteitseisen van gebruikers. Dit document beschrijft de karteermethode en het kwaliteitsprotocol die gehanteerd worden bij actualisaties aan de Geomorfologische kaart van Nederland, om zo de kwaliteit van de geactualiseerde kaart te waarborgen.

De kwaliteitscontrole begint bij het afstemmen van de karteermethode tussen verschillende karteerders door middel van een kwalitatieve en kwantitatieve aanpak. Tijdens het actualiseren wordt de kwaliteit gewaarborgd door een interne controle en achteraf zal de geactualiseerde kaart extern gecontroleerd worden door een gebiedsexpert.

De veldstudie heeft laten zien dat karteerders, zonder onderlinge afstemming, kaarten produceren met een overeenkomst van 60 tot $70 \%$ in pilotgebieden in Zeeland en op de Utrechtse Heuvelrug. Deze overeenkomst zal stijgen na afstemming van karteermethode en geomorfologische classificatie. Deze afstemming zorgt er samen met de interne en externe kwaliteitscontrole voor dat er een consistente en gedetailleerde geactualiseerde kaart geproduceerd zal worden. 



\section{Literatuur}

BRO (2020). Basisregistratie Ondergrond (BRO) Catalogus Geomorfologische kaart. Versie 0.99. Ministerie van Binnenlandse Zaken en Koninkrijksrelaties.

Climate Adaptation Services (2018). Klimaateffectatlas Ede. https://climadapserv.maps.arcgis.com/apps/MapSeries/index.html?appid=66ac247a35ef4b27a8e3 66ce62dc0bc4

Cohen, K.M., E. Stouthamer, W.Z. Hoek, H.J.A. Berendsen, H.F.J. Kempen (2009). Zand in banen zanddieptekaarten van het Rivierengebied en het IJsseldal in de provincies Gelderland en Overijssel. Provincie Gelderland, Arnhem.

Jongmans, A.G., M.W. Van den Berg, M.P.W. Sonneveld, G.J.W.C. Peek, R.M. Van den Berg van Saparoea (2013). Landschappen van Nederland. Wageningen Academic Publishers.

Knol, W.C., H. Kramer, H. Gijsbertse (2004). Historisch grondgebruik Nederland; een landelijke reconstructie van het grondgebruik rond 1900. Alterra, Wageningen UR. Alterra-rapport 573.

Koomen, A.J.M., G.J. Maas (2004). Geomorfologische kaart Nederland (GKN); achtergronddocument bij het landsdekkende digitale bestand. Alterra, Wageningen. Alterra-rapport 1039.

Landschapsbeheer Drenthe. 2020. Pingo Programma Drenthe. http://www.pingoruines.nl/pingoprogramma/

Maas, G.J., W.M. van der Meij, S.P.J. Van Delft, N. Heidema (2019). Geomorfologische kaart van Nederland 1:50 000 (2019). Toelichting op de legenda. https://legendageomorfologie.wur.nl/

Rensink, E., H.J.T. Weerts, M. Kosian, H. Feiken, D. Jansen, B.I. Smit (2019). Archeologische Landschappenkaart van Nederland, versie 3.0. Rijksdienst voor Cultureel Erfgoed, Amersfoort.

Stouthamer, E., K.M.C. Cohen, W.Z.H. Hoek (2020). De vorming van het land: geologie en geomorfologie. Perspectief uitgevers. 



\section{Verantwoording}

WOt-technical report: 195

BAPS-projectnummer: WOT-04-013-013

Dit project werd uitgevoerd en begeleid door Wageningen Environmental Research (WENR). Het rapport en de methode zijn gereviewd door Kim M. Cohen van Utrecht University. Het rapport is meegelezen door Dorothée van Tol-Leenders en Joop Okx (WENR).

Akkoord Extern contactpersoon

functie: $\quad$ Senior beleidsmedewerker landbouw en digitalisering

naam: $\quad$ Frans Lips

datum: 21 januari 2021

Akkoord Intern contactpersoon

naam: Joop Okx

datum: 23 december 2020 



\section{Verschenen documenten in de reeks Technical reports van de Wettelijke Onderzoekstaken Natuur}

\section{\& Milieu}

168 Arets, E.J.M.M., J.W.H van der Kolk, G.M. Hengeveld, J.P. Lesschen, H. Kramer, P.J. Kuikman \& M.J. Schelhaas (2020). Greenhouse gas reporting of the LULUCF sector in the Netherlands. Methodological background, update 2020.

169 Van Kraalingen, D., E.L. Wipfler, F. van den Berg, W.H.J. Beltman, M.M.S. ter Horst \& J.A. te Roller (2020). User manual for FOCUSSPIN version 3.3.

170 Bos-Groenendijk, G.I., C.A.M van Swaay (2020). Habitatrichtlijnrapportage 2019: Annex B Habitatrichtlijnsoorten; Achtergronddocument.

171 Janssen, J.A.M. (red.), R.J. Bijlsma (red.), G.H.P. Arts, M.J. Baptist, S.M. Hennekens, B. de Knegt, T. van der Meij, J.H.J. Schaminée, A.J. van Strien, S. Wijnhoven, T.J.W. Ysebaert (2020). Habitatrichtlijnrapportage 2019: Annex D Habitattypen. Achtergronddocument.

172 Van Kleunen, A., M. van Roomen, E. van Winden, M. Hornman, A. Boele, C. Kampichler, D. Zoetebier, H. Sierdsema \& C. van Turnhout (2020). Vogelrichtlijnrapportage 2013-2018 van Nederland - status en trends van soorten.

173 Glorius, S.T., A. Meijboom (2020). Ontwikkeling van de bodemdiergemeenschap in de geulen van referentiegebied Rottum; Tussenrapportage 13 jaar na sluiting (najaar 2018).

174 Kuindersma, W., D. van Doren, R. Arnouts, D.A. Kamphorst, J.G. Nuesink, E. de Wit-de Vries (2020). Realisatie Natuurnetwerk door provincies. Achtergrondstudie bij de Tweede Lerende Evaluatie Natuurpact.

175 Bouwma, I.M., D.A. Kamphorst, D. van Doren, T.A. de Boer, A.E. Buijs, C.M. Goossen, J.L.M. Donders, J.Y. Frissel, S. van Broekhoven (2020). Provinciaal beleid voor maatschappelijke betrokkenheid bij natuur het beleid nader bekeken in 8 casussen. Achtergrondstudie bij de Tweede Lerende Evaluatie Natuurpact.

176 Gerritsen, A.L., H. Agricola, C. Aalbers, J. van Os (2020). Natuur en landbouw verbinden. Achtergrondstudie bij de Tweede Lerende Evaluatie Natuurpact.

177 Brouwer, F., D.J.J. Walvoort (2020). Basisregistratie Ondergrond (BRO) Actualisatie bodemkaart. Herkartering van de veengebieden aan de flanken van de Utrechtse Heuvelrug.

178 Bruggen, C. van, A. Bannink, C.M. Groenestein, J.F.M. Huijsmans, L.A. Lagerwerf, H.H. Luesink, G.L. Velthof \& J. Vonk (2020). Emissies naar lucht uit de landbouw, 1990-2018; Emissies van ammoniak, stikstofoxide, lachgas, methaan, niet-methaan vluchtige organische stoffen, fijnstof en koolstofdioxide uit kalkmeststoffen - Berekeningen met het model NEMA.
179 Knegt, de B., M. Pleijte, E. de Wit-de Vries, I. Bouwma, F. Kistenkas, W. Nieuwenhuizen (2020). Samenhang Klimaatakkoord en natuurbeleid. Proces en implementatie van het Klimaatakkoord door provincies en maatschappelijke partijen en de potentiële effecten op biodiversiteitsdoelen van de Vogelen Habitatrichtlijn.

180 Mattijssen T.J.M., M. Pleijte, J. Dengerink, T. Koster, M. Visscher (2020). Indicatoren voor burgerbetrokkenheid bij natuur: een zoektocht naar nieuwe aanknopingspunten voor monitoring.

181 Kamphorst, D.A., M. Pleijte, F. Kistenkas (2020). Uitvoering van de Vogel- en Habitatrichtlijn in de praktijk: spanningen en mogelijke oplossingsrichtingen.

182 Elschot K., M.E.B. Van Puijenbroek, D.D.G. Lagendijk, J-T. Van der Wal, C. Sonneveld (2020). Lange-termijnontwikkeling van kwelders in de Waddenzee (1960-2018).

183 Koffijberg K., P. de Boer, S.C.V. Geelhoed, J. Nienhuis, K. Oosterbeek, J. Postma (2020). Broedsucces van kustbroedvogels in de Waddenzee in 2018.

184 IJsseldijk, L.L., M.J.L. Kik, L. van Schalkwijk \& A. Gröne (2020). Postmortaal onderzoek van bruinvissen (Phocoena phocoena) uit Nederlandse wateren, 2019. Biologische gegevens, gezondheidsstatus en doodsoorzaken.

185 Os, J. van, L.J.J. Jeurissen, J.C. Verkaik (2020). Rekenregels schapen en geiten voor de landbouwtelling; Verantwoording van het gebruik van het Identificatie \& Registratiesysteem.

186 Bakker, G., M. Heinen, H.P.A. Gooren, W.J.M. de Groot, P.D. Peters (2020). Hydrofysische gegevens van de bodem in de Basisregistratie Ondergrond (BRO) en het Bodemkundig Informatie Systeem (BIS); Update 2019.

187 Kuindersma, W., E. de Wit - de Vries, F.G. Boonstra, M. Pleijte, D.A. Kamphorst (2020). Het Nederlandse natuurbeleid in zijn institutionele context. Beschrijving en analyse van de interne en externe congruentie van het Nederlandse natuurbeleidsarrangement in relatie tot landbouwbeleid, waterbeleid (voor de grote rivieren) en recreatiebeleid (1975-2018).

188 Kuiters, A.T., G.A. de Groot, D.R. Lammertsma, H.A.H. Jansman, J. Bovenschen (2020). Genetische monitoring van de Nederlandse otterpopulatie; Ontwikkeling van populatieomvang en genetische status 2019/2020.

191 Hennekens, S., J. Holtland, N. van Rooijen, W. Wamelink \& W. Ozinga (2020). Indicatiewaarden voor voedselrijkdom van de 
bodem; een vergelijking tussen drie indicatiesystemen.

192 Glorius, S.T. \& A. Meijboom (2020). Ontwikkeling van enkele droogvallende mosselbanken in de Nederlandse Waddenzee; situatie 2019.

193 Glorius, S.T. \& A. Meijboom (2020). Ontwikkeling van de bodemdiergemeenschap in de geulen van referentiegebied Rottum; Tussenrapportage 14 jaar na sluiting (najaar 2019).

194 Adams, A.S. \& W.J. Remmelts (2020). Achtergronddocumentatie Vogel- en Habitatrichtlijnrapportage Annex A.

195 Van der Meij, W.M. \& G.J. Maas (2020). Kwaliteitsdocument van de Geomorfologische kaart van Nederland. 



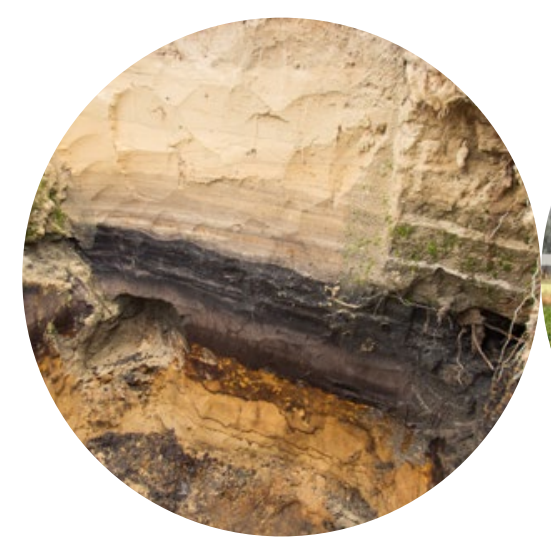

Thema Basisregistratie Ondergrond Wettelijke Onderzoekstaken Natuur \& Milieu

Postbus 47

6700 AA Wageningen

T (0317) 485471

E info.wnm@wur.nl

ISSN 2352-2739

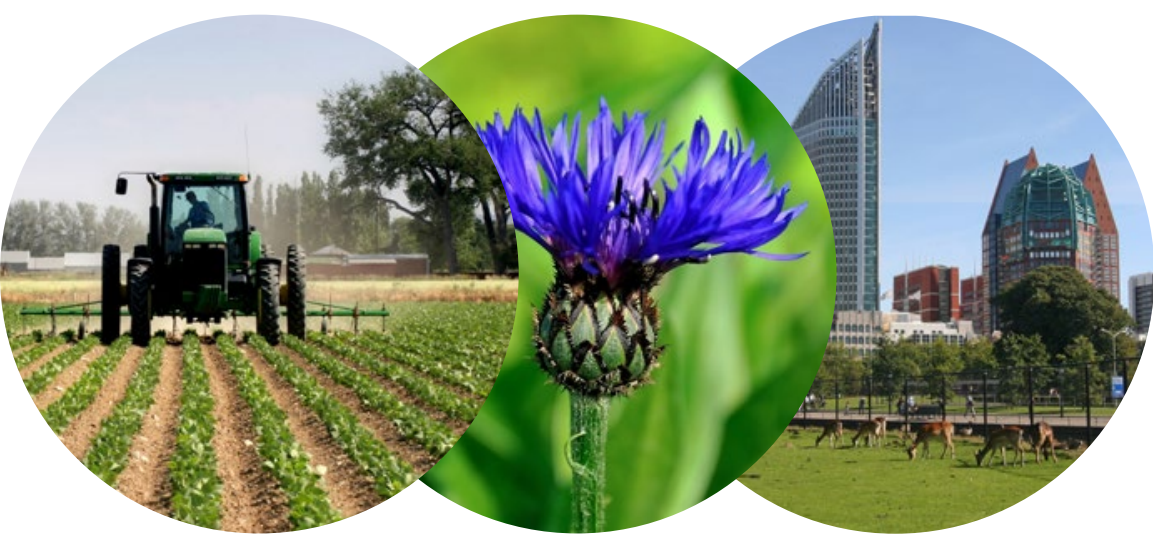

De missie van Wageningen University \& Research is 'To explore the potential of nature to improve the quality of life'. Binnen Wageningen University \& Research bundelen Wageningen University en gespecialiseerde onderzoeksinstituten van Stichting Wageningen Research hun krachten om bij te dragen aan de oplossing van belangrijke vragen in het domein van gezonde voeding en leefomgeving. Met ongeveer 30 vestigingen, 6.500 medewerkers ( $5.500 \mathrm{fte}$ ) en 12.500 studenten behoort Wageningen University \& Research wereldwijd tot de aansprekende kennisinstellingen binnen haar domein. De integrale benadering van de vraagstukken en de samenwerking tussen verschillende disciplines vormen het hart van de unieke Wageningen aanpak. 